\title{
ADAPTACIÓN DE ESPECIES DE BAMBÚ DE CLIMA TEMPLADO EN CHILE
}

\author{
Marlene González ${ }^{1}$, Jorge Campos y Jorge Cabrera
}

\section{RESUMEN}

Los bambúes pertenecen a la familia Poaceae, sub familia Bambusoideae, tribu Bambusaceae. Existen unos 70 géneros y unas 1.450 especies que se distribuyen naturalmente en el este de Asia, el oeste de India y los Himalayas, el norte de Australia, África sub sahariana y América, abarcando una variedad de climas, desde zonas frías de montañas y zonas cálidas tropicales, entre los $50^{\circ} \mathrm{LN}$ y los $47^{\circ} \mathrm{LS}$. Algunas de sus especies están entre las plantas de más rápido crecimiento en el mundo.

Los bambúes son especies multipropósito, que pueden generar una gran variedad de productos, como materiales de construcción, pulpa y papel, tableros, energía, medicinas, alimentos, ornamentación y muchos otros. Numerosos países en el mundo los cultivan intensamente para diferentes productos y en rotaciones muy reducidas. Como ejemplo, China dispone de unos 6 millones de hectáreas de plantaciones, India desarrolla un ambicioso plan para llegar en los próximos años a 2 millones de hectáreas y Brasil posee ya 200 mil hectáreas.

En Chile, existen 13 especies de bambúes nativos, todas pertenecientes al género Chusquea, que se caracterizan por ser sólidos, de pequeño diámetro y baja altura. Las más conocidas son colihue (Chusquea culeou) y quila (Chuquea quila). No existe mayor información en el país sobre bambúes, solo se han hecho algunos estudios para colihue y quila referentes a tableros ornamentales, carbón y derivados, y en cuanto a especies exóticas existe un bambucetum en Valdivia, y algunas plantaciones en Talagante y en la Isla de Pascua.

La multiplicidad de usos, el rápido crecimiento y la reducida rotación de estas especies motivaron al Instituto Forestal a desarrollar un proyecto de investigación, apoyado por FONDEF (Fondo de Fomento al Desarrollo Científico y Tecnológico de CONICYT), orientado a probar en el país la adaptación y crecimiento de una selección de especies exóticas de bambúes a importar desde China, Ecuador y otros países.

Mediante comparación climática entre lugares de origen y diferentes zonas del país, y considerando crecimiento y potencial productivo, se seleccionó un total de 28 especies a introducir experimentalmente y en el año 2008 se establecieron 12 ensayos entre las regiones Metropolitana y Los Lagos. En el presente trabajo se entregan resultados preliminares obtenidos en estos ensayos.

Palabras clave: Bambusaceae, bambú, introducción de especies 


\section{SUMMARY}

Bamboos belong to the Poaceae family, Bambusoideae sub family and Bambusaceae tribe. There are some 70 genera and 1,450 species and the natural distribution is Eastern Asia, Western India and the Himalayas, Northern Australia, sub Saharan Africa and America, through a variety of site conditions from cold mountains to hot tropical zones, between $50^{\circ} \mathrm{NL}$ and $47^{\circ} \mathrm{SL}$. Some of the bamboos species are within the faster growing plants in the world.

Bamboos are multipurpose species that can offer a number or products, such as building materials, pulp and paper, boards, energy, medicines, animal and human foods, landscape and many others. Several countries cultivate them intensively for different products in short rotations. For instance, China has 6 million hectares of Bamboo plantations, India is right now developing an ambitious program to have some 2 million hectares by the next few years, and Brazil already has 200 thousand hectares.

In Chile, there are 13 species of native bamboos, all them belonging to the Chusquea genus, characterized for being solid, with a short diameter and a reduced height. Best known are Colihue (Chusquea culeou) and Quila (Chuquea quila). There is very short information on bamboos in the country, only some studies related to ornamental boards, charcoal and derivatives with Colihue and Quila, and regarding to exotic species there is a Bambucetum in Valdivia and some small area plantations in Talagante, near Santiago, and in Eastern Island.

The wide variety of uses, the fast growth and the short rotation of these species motivated the Chilean Forestry Institute to carry out a research project, under the FONDEF support (Scientific and Technologic Developing Promotion Fund of CONICYT), in order to try in the country the adaptation and growing of a selected number of Bamboo species to be imported from China, Ecuador and other countries.

Through climate matching between provenance regions and different areas of the country and considering potential growth and productivity, a total of 28 species were selected for experimental introduction, and during 2008 a set of 12 trials were established between the Metropolitana and Los Lagos regions. The present paper shows preliminary results from those trials.

Key words: Bambusaceae, bamboo, species introduction 


\section{INTRODUCCIÓN}

En el mundo hay una gama muy importante de Productos Forestales No Madereros (PFNM), entre los que se encuentran aquellos generados por los bambúes, especies gramíneas que presentan las más altas tasas de crecimiento dentro de las especies vegetales y permiten su utilización en más de 1.500 productos diferentes. El bambú y el ratán en conjunto, representan en el mundo un comercio de US\$14 billones/año y dan trabajo a miles de personas (INBAR, 2010).

El bambú se ha empleado desde siempre, sin embargo más recientemente, ante la carencia de fibras naturales y productos leñosos para la producción de pulpa y papel, y la fabricación de muebles y elementos para la construcción, ha sido revalorizado por los países productores, modificando su empleo como materia prima de uso casi exclusivamente artesanal, hacia la generación de productos industriales, a través del mejoramiento y aplicación de tecnologías.

De igual manera, se han incrementado las plantaciones de las mejores especies de bambú, particularmente en los países con tradición en este rubro; por ejemplo China tiene cerca de 6 millones de hectáreas plantadas, Brasil alcanza a 200.000 ha, e India ha desarrollado recientemente un plan para contar con 2 millones de hectáreas plantadas, a fines del año 2017. Actualmente también existen plantaciones en Europa y en el norte de Estados Unidos, pero de menores extensiones y con un fin más bien ornamental.

Existen aproximadamente 1.350 especies de bambúes (Hidalgo, 2003), un grupo de los cuales se desarrolla en climas templados, soportando temperaturas de hasta $-18^{\circ}$ C. Tienen importantes usos, como brotes comestibles para humanos, hojas palatables para animales, madera, fibra para producción de pulpa y papel, fibra para producción de textiles, protección de taludes y riberas de ríos, artesanías, muebles, elementos para la construcción y muchos otros usos, entre ellos los ambientales.

La distribución natural de los bambúes se concentra en Asia y América, y se ha demostrado científicamente que aún cuando son continentes separados físicamente, sus especies están relacionadas (Oprins et al., 2002). Abarcan desde los $46^{\circ}$ de latitud norte hasta aproximadamente los $47^{\circ}$ de latitud sur y desde el nivel del mar hasta los $4.000 \mathrm{~m}$ de altitud en los Andes Ecuatoriales, lo que demuestra su gran adaptabilidad a diferentes condiciones de clima y suelos (Botero, 2006).

Gratani et al. (2008) señalan que su distribución natural comprende el este de Asia desde los $50^{\circ} \mathrm{LN}$, el norte de Australia, el oeste de India y los Himalayas, África subsahariana y también América, desde el sureste de los Estados Unidos hasta el sur de Argentina y Brasil hasta los $47^{\circ} \mathrm{LS}$.

Los bambúes pertenecen a la familia Poaceae, sub familia Bamusoideae, tribu Bambusaceae, la cual se subdivide en 9 sub tribus. Gratani et al. (2008) indican que existen más de 70 géneros y unas 1450 especies en estos, y Farrelly (1984) señala que se encuentran entre las plantas de más rápido crecimiento en el mundo, habiéndose registrado para algunas especies incrementos de 1 m y más por día. 
En su distribución natural destacan varios géneros, entre ellos Phyllostachys y Semiarundinaria, que alcanzan entre 4 y 15 metros de altura y presentan variados colores y mezclas de ellos en sus culmos (nombre que reciben sus tallos), desde amarillos, pasando por una variada gama de verdes, hasta totalmente negro; en zonas más tropicales se encuentran los géneros Bambusa y Dendrocalamus, donde algunas de sus especies alcanzan hasta $30 \mathrm{~m}$ de altura. En China y Japón también se desarrollan especies de menor tamaño como Pseudosasa, Pleioblastus, Sasa y Arundinaria; en zonas montañosas y frías en China, es posible observar los géneros Fargesia, Thamnocalamus y Yushania (Oprins et al., 2002). En América existen 45 géneros y 515 especies, que se distribuyen desde los Estados Unidos, a lo largo y ancho de Centro y Sudamérica, en las Islas del Caribe, hasta el sur de Chile, destacando los géneros Arthrostylidium, Guadua y Rhipidicladum (Botero, 2006).

La estructura de sus culmos, funciona como un muy efectivo sistema de transporte, almacenamiento y crecimiento y es precisamente la base para los distintos usos que se da a estas especies (Oprins et al., 2002), ya que las propiedades mecánicas y de trabajabilidad están dadas por su estructura anatómica (diámetro y largo de fibra, grosor de pared de la fibra, entre otros factores) (Botero, 2006).

Existe una serie de técnicas disponibles para la propagación de bambú, incluyendo varios métodos clásicos, como por semillas, esquejes y división del rizoma, pero cada uno de ellos es aplicable sólo a determinadas especies, y no todos son adecuados para la propagación a gran escala. En el último tiempo, también se ha trabajado con micropropagación, técnica con la que se han conseguido mejores resultados que con las técnicas tradicionales (Oprins et al., 2002).

La situación en los distintos países de América Latina, en lo que respecta a la investigación y empleo productivo de los bambúes (tanto locales como introducidos), es desigual, e incluso en muchos de ellos se aprecia una destrucción progresiva de este recurso, por explotación indiscriminada o habilitación de terrenos para agricultura, ganadería o forestación (Botero, 2006). Sin embargo, se ha observa un interés creciente en la plantación y cultivo de diferentes especies de bambúes para contribuir a la generación de materia prima sustitutiva de la madera (INBAR, 2010).

Los bambúes no reemplazan a las especies leñosas, para las cuales la tecnología de procesamiento está muy desarrollada, por el contrario, se ha demostrado que la producción de bambú puede ser complementaria a las plantaciones forestales existentes, agregando nuevos productos. Adicionalmente, es importante indicar que un alto porcentaje de la infraestructura existente para procesar especies leñosas puede ser utilizada de igual manera o adaptada para el procesamiento de bambúes lignificados, como es el caso de la industria de pulpa y papel, tableros encolados, tableros aglomerados, chapas y muebles, principalmente.

Chile es un país forestal, cuenta con más de 13 millones de hectáreas de bosques nativos y más de 2 millones de hectáreas de plantaciones forestales, además de un fuerte desarrollo industrial basado en estas últimas. Sin embargo, las plantaciones forestales son en la actualidad fundamentalmente de pino radiata (Pinus radiata), unos 1,4 millones 
de hectáreas, y eucalipto (Eucalyptus globulus y Eucalytus nitens), unos 0,7 millones de hectáreas, de modo que todo el desarrollo alcanzado se basa muy mayoritariamente en dos o tres especies, dado que los bosques nativos tienen una participación muy marginal en la corta anual de madera para fines industriales (INFOR, 2010). Aún así, existen importantes superficies de suelos de aptitud forestal que pueden incorporarse a la actividad productiva con nuevos cultivos exóticos o nativos, pero para ello se requiere profundizar los conocimientos y orientar las acciones para lograr su ordenación bajo los criterios de sostenibilidad, independiente del uso que se esté fomentando. En este contexto es deseable la diversificación de las especies forestales plantadas para la producción de fibra, madera y también la de productos forestales no madereros (PFNM) (Campos et al., 2003), de manera de lograr un aprovechamiento de los recursos con la máxima eficiencia privada y social.

Adicionalmente, y considerando las evidencias de modificaciones futuras del clima a nivel mundial, se reafirma la hipótesis de disponer de una gama más amplia de especies que puedan prosperar en condiciones diferentes y de borde, sustituyendo o complementando a las especies vegetales actuales, que podrían verse afectadas negativamente por las variaciones climáticas que se prevén; mayores temperaturas y cambios en los regímenes pluviométricos.

El disponer de otras especies de uso industrial, que tienen un amplio grado de dispersión climática, es favorable frente a contingencias de este tipo, particularmente cuando se trata de un recurso complementario, que no sustituye a otros y que, por el contrario, amplía la gama de opciones productivas. Adicionalmente, el bambú es uno de los mejores protectores de suelos y es muy adecuado para plantar en quebradas y bordes de cursos de agua, cumpliendo el doble papel de protector y productor, especialmente por su sistema de rizomas y raíces y por su constante generación de brotes y culmos (Rao, 1995).

En Chile, el Instituto Forestal (INFOR) ha colaborado en proyectos referentes a bambúes autóctonos, desarrollados inicialmente por INTEC-CHILE y posteriormente por Fundación Chile en conjunto con la Universidad Austral y un grupo de empresarios, para lo que se ha contado con el apoyo y financiamiento de FONDEF-CONICYT.

En Chile, existen 13 especies de bambúes nativos, todas pertenecientes al género Chusquea, que se caracterizan por ser sólidos, de pequeño diámetro y baja altura. Se ha trabajado en proyectos para su utilización, referentes a tableros ornamentales, carbón y derivados, y otro relacionado con transferencia tecnológica, cuyo resultado principal contemplaba la formación de una central de acopio de coligüe (Chusquea culeou).

No se había estudiado la posibilidad de adaptar especies exóticas, de las mejores especies de bambú con fines industriales, a las condiciones agroclimáticas de Chile. Solo hay pequeñas muestras de adaptación de algunas especies de bambú que fueron traídas a Chile básicamente con fines ornamentales. Ejemplos de esto son el Bambucetum de la Universidad Austral (Región de Los Ríos) y las plantaciones con Phyllostachys heterocycla, instaladas por un particular en las cercanías de Talagante, en la Región Metropolitana. 
En este marco, se desarrolló el proyecto "Adaptación de especies de bambú de clima templado en Chile", coordinado por INFOR y que además contó con la participación de MOST (Ministerio de Ciencia y Tecnología de la República Popular China), AGCl (Agencia de Cooperación Internacional del Gobierno de Chile), CONAF (Corporación Nacional Forestal), empresas y propietarios particulares, además de otras instituciones.

El objetivo planteado fue evaluar la adaptabilidad y crecimiento de 28 especies exóticas de bambú de clima templado entre las Regiones Metropolitana y Aysén, además de Isla de Pascua, a través del establecimiento de plantaciones experimentales, apuntando a encontrar nuevas alternativas productivas y a futuro conocer su manejo, industrialización, utilización y comercio, lo que podría generar importantes impactos económicos y sociales al aportar a la sociedad opciones de desarrollo productivo y social en armonía con el medio.

Asimismo, la adaptación y plantación industrial de algunas especies de bambú podría constituir una nueva fuente de ingresos para los agricultores, tanto por poder entregar al mercado materias primas de carácter industrial (por ejemplo principios activos para la medicina y agricultura), como por su utilización directa en el campo (en construcción, tutores, cercos, elementos para la fabricación de muebles, brotes comestibles y otros productos).

Debe considerarse también la generación de nuevas fuentes de trabajo, protección del suelo y medioambiente y la sustitución de importaciones. Se podría por ejemplo utilizar superficies pequeñas para la generación de productos complementarios en terrenos de pequeños productores agrícolas y forestales.

Las oportunidades de generar nuevos productos en períodos más cortos, con cosechas anuales, constituiría una ventaja para campesinos y agricultores, de manera de permitir obtener ingresos anuales, a diferencia de los plazos conocidos para los cultivos forestales más tradicionales, que exigen rotaciones más largas, respondiendo así a los principios establecidos a nivel de país, frente a lograr el desarrollo de la Agricultura Familiar Campesina (AFC).

Existe bastante investigación a nivel mundial acerca de las características de las especies, en cuanto a sus propiedades físico-mecánicas, tecnología de uso, comercialización y otras variables. Además, es importante indicar que no existen en el país especies que tengan la potencialidad de generación de biomasa a las altas tasas de crecimiento que presentan algunos de los bambúes a adaptar. Tampoco existe la materia prima bambú de las características de los bambúes exóticos, como los que eventualmente se importan, de grandes diámetros y longitudes, desde Ecuador y Colombia, para su uso en proyectos decorativos en construcciones.

Hay que considerar también que una misma planta puede ser considerada multipropósito, ya que las diferentes partes de estas especies permiten ser usadas en diferentes usos maximizando así su utilidad y rendimiento. Es así como las dos primeras trozas de un culmo son aptas para la producción de madera para tableros, parquet y muebles, las siguientes para la producción de pulpa y papel, las siguientes para textiles, 
las siguientes para tutores, las ramas y hojas para forraje y los rizomas para artesanías. En algunas especies incluso sus brotes son consumidos como alimento.

\section{OBJETIVOS}

Mediante una adecuada selección de especies, basada en sus características específicas y en las condiciones agroclimáticas de origen y destino, podría identificarse las más apropiadas para la creación de nuevos recursos en distintas regiones del país. Todo ello a través de un diseño de investigación basado en el establecimiento de parcelas experimentales para la evaluación de supervivencia y crecimiento de diferentes especies.

El objetivo general es probar la adaptación de especies exóticas de bambú de climas templados para uso industrial en diferentes regiones agroclimáticas de Chile.

Los objetivos específicos son seleccionar diferentes condiciones agroclimáticas en el país y establecer en ellos ensayos de adaptación de especies de bambú mediante parcelas de crecimiento que serán periódicamente controladas.

\section{MATERIAL Y METODO}

\section{Distribución de los Ensayos}

Para determinar la adaptación de las especies, se planteó probarlas en diferentes zonas del país, abarcando desde la Región Metropolitana hasta la Región de Aysén, incluyendo además la Isla de Pascua, dado que corresponde al único lugar del país donde ya existen plantaciones de bambú (Bambusa vulgaris) como barreras de protección para cultivos agrícolas (Figura $\mathrm{N}^{\circ} 1$ ).
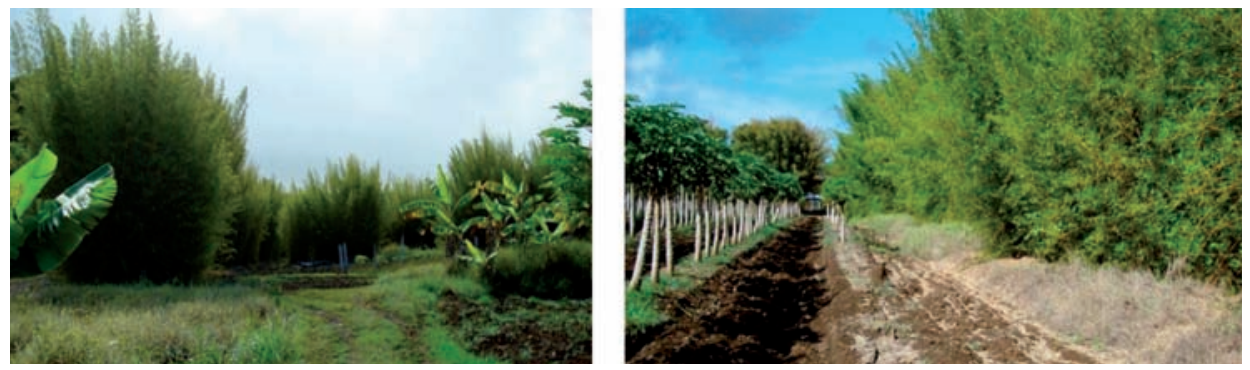

Figura $\mathrm{N}^{\circ} 1$

\section{PLANTACIONES DE BANANOS Y PAPAYOS PROTEGIDAS POR CORTINA CORTAVIENTO DE Bambusa vulgaris ISLA DE PASCUA}

El proyecto se plantea establecer parcelas experimentales en zonas de cordillera y costa en diferentes latitudes, de manera de representar diferentes regiones agroclimáticas. Se espera inicialmente cubrir un total de 12 zonas agroclimáticas (Cuadro $N^{\circ} 1$ ), distribuidas en 15 sectores, en cada uno de los cuales se instalarán 12 parcelas; 11 con especies exóticas más un testigo de especie nativa. 


\section{Cuadro $\mathrm{N}^{\circ} 1$ \\ ZONAS AGROCLIMÁTICAS A CUBRIR}

\begin{tabular}{|l|l|}
\hline \multicolumn{2}{|c|}{ ZONAS AGROCLIMÁTICAS } \\
\hline Santiago & Valdivia \\
\hline Talca & Osorno \\
\hline Chillán & Puerto Montt \\
\hline Concepción & Chiloé \\
\hline Victoria & Patagonia \\
\hline Temuco & Islas \\
\hline
\end{tabular}

La selección de los sitios para los ensayos dentro de las distintas zonas agroclimáticas fue realizada considerando las características climáticas, los antecedentes bibliográficos de las especies y consultas a expertos, tanto nacionales como extranjeros.

En base a la revisión de las características agroclimáticas de las regiones centrales y sur del país, finalmente se definieron 10 zonas agroclimáticas de interés, dentro de las cuales se distribuyeron 15 sectores para la instalación de los ensayos (Cuadro № 2 y Figura $\left.\mathrm{N}^{\circ} 2\right)$.

\section{Cuadro № 2 \\ SITIOS DE ENSAYO SEGÚN ZONAS AGROCLIMÁTICAS}

\begin{tabular}{|l|l|l|l|}
\hline \multicolumn{1}{|c|}{ ZONAS } & \multicolumn{3}{|c|}{ SITIOS DE ENSAYOS } \\
\hline Santiago & 1. Talagante & & \\
\hline Talca & 2. Curicó & & \\
\hline Concepción & 3. Cañete & & \\
\hline Temuco & 4. Villarrica & & \\
\hline Victoria & 5. Toltén & & \\
\hline Valdivia & 6. Panguipulli & 7. Valdivia & 8. Neltume \\
\hline Puerto Montt & 9. Puerto Varas & 10. Calbuco & \\
\hline Chiloé & 11. Castro & 12. Chonchi & \\
\hline Patagonia & 13. Aysén & & \\
\hline Islas & 14. y 15. Isla de Pascua & \\
\hline
\end{tabular}


Se decidió no incluir las zonas agroclimáticas Chillán y Osorno de la preselección original, ya que no presentan grandes diferencias respecto de zonas como Talca y Puerto Montt, respectivamente.

Además de las variables climáticas; temperaturas, precipitación, número de días con helada, y otras, se traslapó esta información con la entregada por el programa computacional Bamboo Species-to-Site Matching diseñado por INBAR.

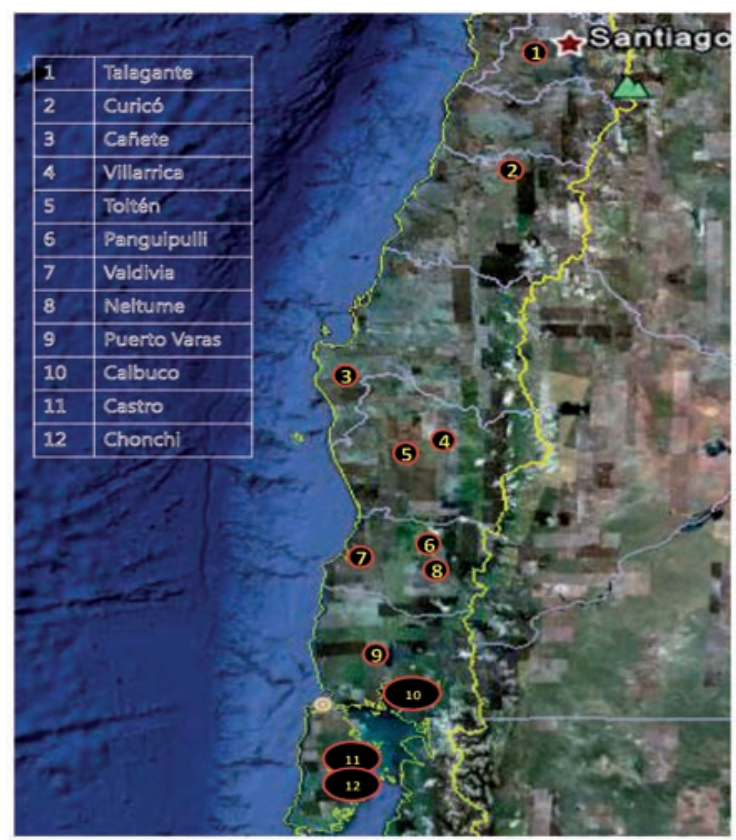

\section{Figura $\mathrm{N}^{\circ} 2$ \\ DISTRIBUCIÓN DE LOS ENSAYOS REGIONES METROPOLITANA A LOS LAGOS}

Se efectuaron recorridos por los sitios preseleccionados con expertos invitados por el proyecto, quienes entregaron mucha información de interés a los propietarios respecto a los cuidados iniciales de las plantaciones y los mejores sitios dentro de cada predio, de manera de asegurar mejores resultados, evitando zonas inundables, suelos particularmente pobres y otras situaciones de riesgo para los ensayos (Figura $\mathrm{N}^{\circ} 3$ ). 

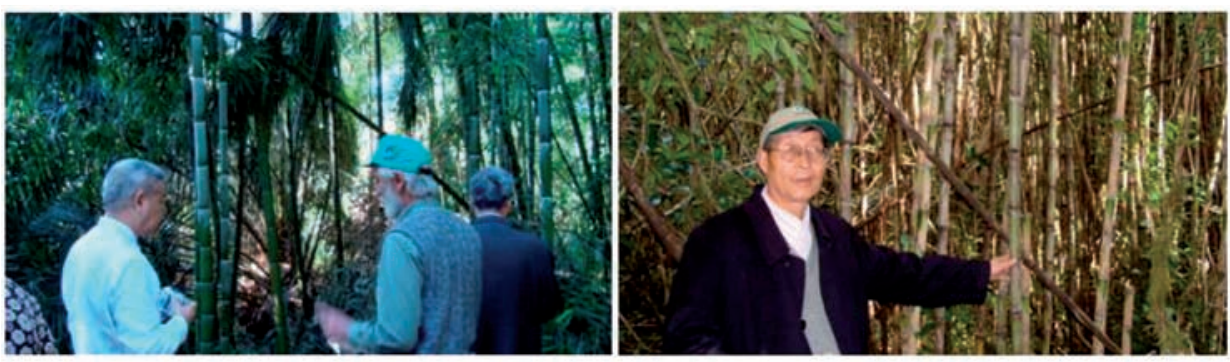

Figura $N^{\circ} 3$

EXPERTOS CHINOS EN VISITA A PREDIOS DE ASOCIADOS AL PROYECTO

\section{Selección de Especies}

La investigación y el desarrollo de tecnologías para las Bambusaceas presentan un importante avance a nivel mundial, por ello la mayor parte de las especies más conocidas ha sido probada en distintas regiones del mundo. Existe también claridad respecto a los usos principales de cada una de ellas, antecedentes que fueron considerados al momento de la elección de las especies a ensayar en Chile, conjuntamente con las características de clima de cada zona.

Se decidió trabajar con un total de 28 especies de Bambusaceas exóticas, que serían importadas desde distintas regiones del mundo; Asia, Europa y América del Sur, de acuerdo a la disponibilidad de cada una de ellas. Además, se consideraron dos especies chilenas que actuarían como testigo en los ensayos: Chusquea culeou (coligüe) en la Zona Sur y Chusquea cumingii (quila del norte) en la zona Centro Sur, las que serían producidas en viveros de las Regiones de Valparaíso y Los Ríos, respectivamente.

La preselección de las 28 especies posibles de adaptar se efectuó de acuerdo a sus características de crecimiento y a las condiciones ambientales en sus lugares de origen, consultándose una cantidad de fuentes de información, las principales de las cuales son las siguientes:

- Red de Trabajo Internacional para Bambú y Ratán INBAR² (por su sigla en inglés).

Software especializado de INBAR "Bamboo species - to - Site Matching". Este software permite identificar las especies aptas para diferentes regiones climáticas del mundo y entrega información de cada especie en cuanto a distribución actual y potencial, requerimientos agroclimáticos, temperaturas, usos, además de otras variables de interés (Figura $N^{\circ} 4$ ).

Es una primera aproximación a las especies posibles de cultivar, pero que 
debe ser revisada con especialistas que puedan señalar particularidades de las especies y su silvicultura.

- Revisión del listado de las 20 especies seleccionadas como las mejores en el mundo por INBAR (INBAR, 2007). Esta información se actualiza en forma permanente, de acuerdo a los resultados registrados en distintas investigaciones realizadas en el mundo.

- Bibliografía con las características de las especies de mayor tamaño que crecen en clima templado (Villegas, 1996; Singh et al., 2004; Dransfield et al., 1995, entre las principales).

- $\quad$ Consultas a especialistas en silvicultura de bambú de INBAR, entre ellos:

Álvaro Cabrera, Consultor de FAO, que trabaja para INBAR en la Oficina para América Latina en Guayaquil.

Profesor Zhu Zhaohua, experto chino en materia de introducción de especies de bambú y sus usos, así como también en las técnicas de reproducción de las mismas; integrante del grupo de asesores de la oficina de INBAR en Beijing.

las siguientes:

Los principales parámetros considerados para la selección de las especies fueron

Rangos de precipitación

Tolerancia de la especie a períodos secos

Rango de temperaturas máximas y mínimas

Tolerancia al frío y a heladas

Diámetros máximos que alcanza la especie en su lugar de origen

Alturas máximas que alcanza la especie en su lugar de origen

Usos principales 

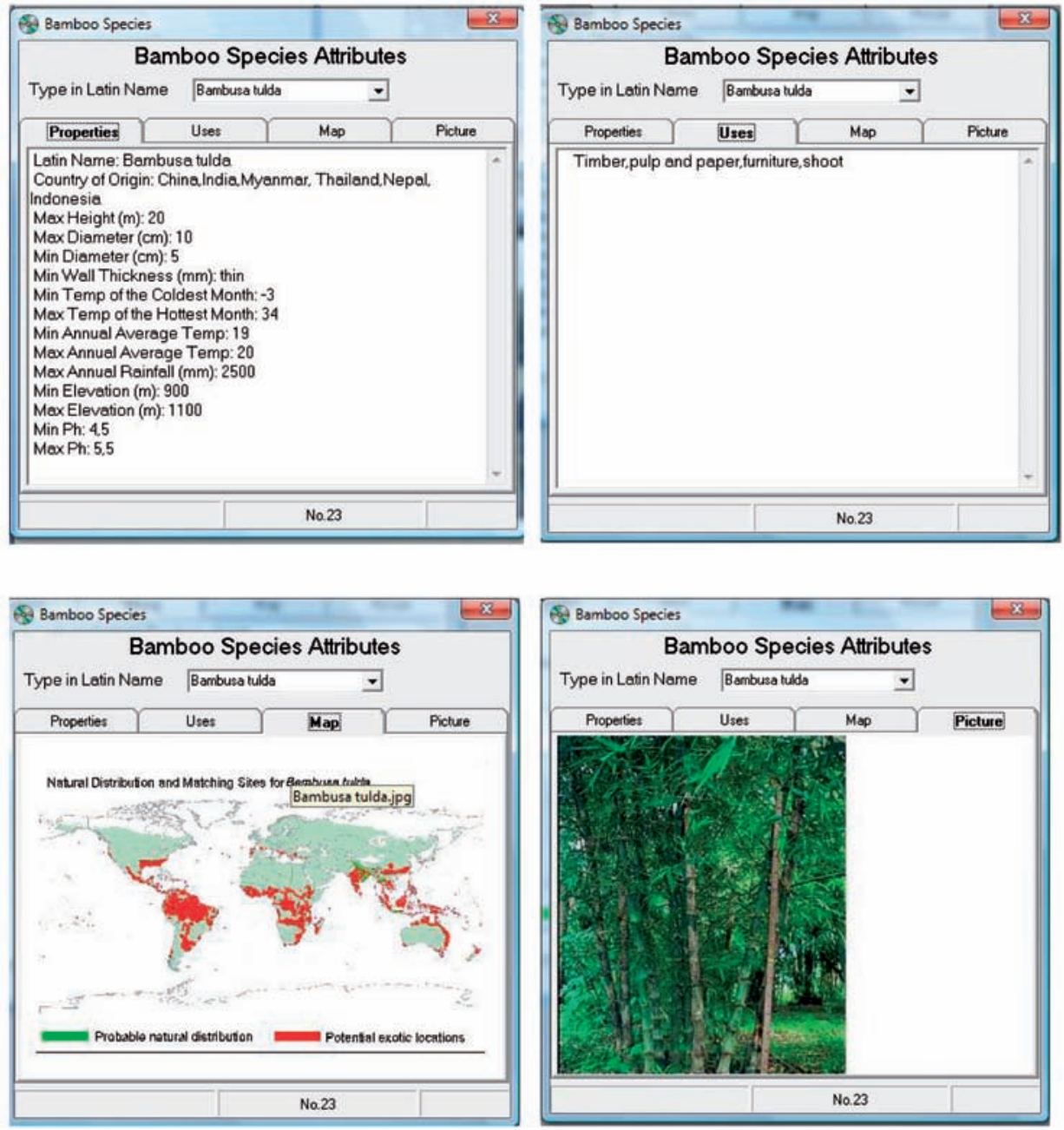

Figura $N^{\circ} 4$

\section{EJEMPLO DE INFORMACIÓN ENTREGADA POR SOFTWARE DE INBAR PARA LA ESPECIE Bambusa tulda.}

Con toda esta información, fue posible definir un primer listado de especies a ensayar (Cuadro $N^{\circ} 3$ ), que comprende 28 especies pertenecientes a 8 géneros. 


\section{Cuadro $\mathrm{N}^{\circ} 3$}

ESPECIES PRESELECCIONADAS PARA ENSAYOS

\begin{tabular}{|c|c|c|c|}
\hline & Nombre científico & Nombre común & Uso principal \\
\hline 1 & Bambusa balcooa & Giant bamboo & Uso múltiple, muebles \\
\hline 2 & Bambusa bambos & Giant thorny & Fibras, brotes \\
\hline 3 & Bambusa blumeana & Thorny branch bamboo & Usos múltiples \\
\hline 4 & Bambusa polymorpha & Thai Bamboo & Brotes \\
\hline 5 & Bambusa textilis & Weavers bamboo & Fibras, tejer, brote \\
\hline 6 & Bambusa tulda & Indian timber bamboo & Construcción \\
\hline 7 & Bambusa vulgaris & Bambú común & Fibras, Pulpa papel \\
\hline 8 & Cephalostachyum pergracile & Mnianmar bamboo & Uso múltiple \\
\hline 9 & Dendrocalamus asper & Phillipines bamboo & Madera \\
\hline 10 & Dendrocalamus giganteus & Giant bamboo & Construcción \\
\hline 11 & Dendrocalamus latiflorus & Great flower bamboo & Multiuso \\
\hline 12 & Dendrocalamus strictus & Bambú macho & Multiuso \\
\hline 13 & Gigantochloa apus & Bambú Tali & Brotes, Construcción \\
\hline 14 & Gigantochloa levis & Brunei bamboo & Brotes, Construcción \\
\hline 15 & Giganochloa sp & Falsa arundina & Brotes, Múltiple \\
\hline 16 & Guadua angustifolia & Caña Guadua & Construcción, múltiple \\
\hline 17 & Guadua chacoensis & Guadua & Construcción, múltiple \\
\hline 18 & Melocanna baccifera & Basso bamboo & Multiuso \\
\hline 19 & Ochlandra spp & Reed bamboo & Multiuso \\
\hline 20 & Phyllostachys atrovaginata & Incense bamboo & Humedales, brotes \\
\hline 21 & Phyllostachys aurea & Bambú dorado & Multiuso, brotes \\
\hline 22 & Phyllostachys bambusoides & Castillonis, Matake & Multiuso, brotes \\
\hline 23 & Phyllostachys heteroclada & Water bamboo & Humedales \\
\hline 21 & Phyllostachys nidularia & Water bamboo & Humedales \\
\hline 25 & Phyllostachys pubescens & Bambú chino, mosso & Multiuso, brotes \\
\hline 26 & Phyllostachys viridis & Viridis bamboo & Multiuso \\
\hline 27 & Phyllostachys glauca & Bambú blanco & Multiuso, brote \\
\hline 28 & Phyllostachys heterocycla & Bambú rayado & Multiuso, brotes \\
\hline
\end{tabular}


Existe cierta preocupación respecto que los bambúes pueden ser invasivos, la cual surge principalmente de la jardinería, donde la invasión se produce en metros y con especies ornamentales, pero en general la mayor parte de los bambúes no tienen esta característica invasiva, de hecho la gran parte de los bambúes en el mundo están en franca regresión.

Las especies comerciales se reproducen mayormente por rizomas y es fácil ponerles un límite si fuera necesario mediante una zanja de $40 \mathrm{~cm}$ o bien una lata, pero normalmente no se hace, ya que al cosechar se controla su regeneración.

Los bambúes se reproducen por semillas en períodos muy largos y además éstas tienen baja vialidad (normalmente uno o dos años), a diferencia de las especies invasoras, como por ejemplo el Ulex europea que además de producir semillas profusamente todos los años, estas tienen una viabilidad de unos 50 años.

Una especie diferente y excepcional es el caso de la quila chilena, que es uno de los pocos bambúes en el mundo que se ramifica y puede trepar por árboles, hasta 20 - 30 m, cosa que ocurre en terrenos que han sido sobreexplotados o quemados.

\section{Diseño Experimental}

Se contempló un diseño experimental simple, de parcelas al azar, de $6 \times 5$ plantas, espaciadas a $3 \times 3 \mathrm{~m}$, dejando una fila de aislación en todas direcciones, de modo que la parcela central de control es de 12 plantas (Figura $N^{\circ} 5$ ).

Dadas las limitaciones previstas para la obtención de material de propagación, se optó por no considerar repeticiones, en consecuencia cada especie en un ensayo estará representada por una parcela de 30 plantas, de las cuales 12 constituirán la parcela central de control. 


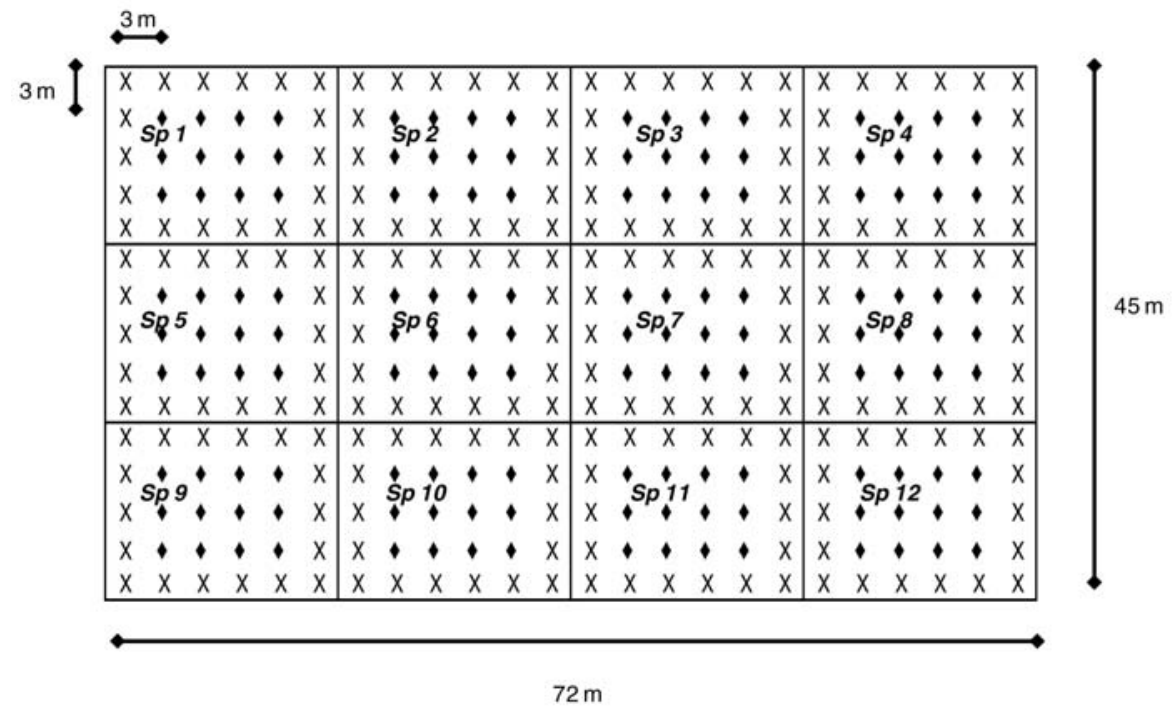

Figura $\mathrm{N}^{\circ} 5$

DISEÑO EXPERIMENTAL

Se emplearán plantas en maceta de $10 \mathrm{~cm}$ de diámetro por $20 \mathrm{~cm}$ de altura, preparación de suelos en casillas de $40 \times 40 \times 40 \mathrm{~cm}$, control de malezas y fertilización específicas para cada ensayo, cerco perimetral permanente y protección individual de las plantas contra lagomorfos en caso necesario.

Las mediciones de control consideran supervivencia (\%), diámetro a $10 \mathrm{~cm}$ de altura $(\mathrm{cm})$, altura total $(\mathrm{m})$ y estado sanitario (coloración, presencia de patógenos). Las mediciones serán trimestrales el primer año y posteriormente semestrales.

\section{Importación del Material de Propagación}

La obtención de material de propagación para las 28 especies se visualizaba como un factor crítico desde la formulación del proyecto, dada la necesidad de internar al país plantas o material para propagación vegetativa y no semillas, para lo cual es necesario ubicar proveedores confiables para cada origen y satisfacer una serie de exigencias y condiciones de la autoridad fitosanitaria, en origen y en destino.

Dados los procedimientos para la obtención del material vegetal necesario y las exigencias y plazos estimados para las diferentes especies y orígenes, analizados en reuniones de coordinación con el Servicio Agrícola y Ganadero (SAG), se optó por trabajar en forma diferenciada con 3 orígenes; Ecuador, Bélgica y China. 
Lamentablemente las dificultades previstas se hicieron realidad y después de un largo proceso y tramitación, y de errores en origen que provocaron la pérdida de algunos envíos por no cumplir cabalmente con las exigencias sanitarias, se pudo obtener plantas de 30 especies, variedades y formas, solo de los géneros Bambusa y Phyllostachys y en general en cantidades menores a las requeridas originalmente.

De Ecuador se obtuvo un total de diez especies y variedades del género Bambusa y de China 20 especies, variedades y formas del género Phyllostachys, y la importación desde Bélgica fue descartada finalmente, dadas todas las dificultades y retrasos ya sufridos por el proyecto (Cuadros $\mathrm{N}^{\circ} 4$ y N ${ }^{\circ} 5$ ).

Dos especies de Ecuador fueron recibidas tardíamente y no se las pudo incluir en los ensayos, y todas las especies importadas de China, además de ser recibidas tardíamente, debieron ser puestas en cuarentena por un período de doce meses.

Esto obligó a replantear los ensayos incluyendo en ellos sólo 8 especies del género Bambusa y una local usada como control (Chusquea culeou). El material restante, 22 especies, variedades y formas, se mantiene en reserva, cuidados y mantención en el Jardín Botánico Nacional de Viña del Mar. Veinte de estas especies bajo cuarentena hasta mitad del año 2011.

\section{Cuadro $\mathrm{N}^{\circ} 4$}

\section{ESPECIES IMPORTADAS DESDE ECUADOR}

\begin{tabular}{|c|c|}
\hline ESPECIE & Plantas $\left(\mathrm{N}^{\circ}\right)$ \\
\hline Bambusa multiplex & 334 \\
\hline Bambusa perviabilis & 212 \\
\hline Bambusa tuldoides & 518 \\
\hline Bambusa tulda & 533 \\
\hline Bambusa tulda var. Vittata & 272 \\
\hline Bambusa ventricosa & 282 \\
\hline Bambusa vulgaris & 647 \\
\hline Bambusa vulgaris var. Vittata & 604 \\
\hline Bambusa guadua ${ }^{3}$ & 200 \\
\hline Bambusa guadua var. Bicolor ${ }^{4}$ & 200 \\
\hline TOTAL & 4.202 \\
\hline
\end{tabular}

Bambusa guadua y Bambusa guadua var. Bicolor recibidas tardíamente 


\section{Cuadro $\mathrm{N}^{\circ} 5$ \\ ESPECIES IMPORTADAS DESDE CHINA EN CUARENTENA EN JARDÍN BOTÁNICO NACIONAL}

\begin{tabular}{|l|l|}
\hline Phyllostachys aureosulcata f. Aureocaulis & Phyllostachys nigra \\
\hline Phyllostachys aureosulcata f. Spectablilis & Phyllostachys nigra f. Localis \\
\hline Phyllostachys bambusoides & Phyllostachys nidularia \\
\hline Phyllostachys bambusoides f. Llacrima-deae & Phyllostachys pinyanensis \\
\hline Phyllostachys dulces & Phyllostachys praecox cv. Prevernalis \\
\hline Phyllostachys glabrata & Phyllostachys prominens \\
\hline Phyllostachys glauca & Phyllostachys propincua \\
\hline Phyllostachys heteroclada & Phyllostachys sulphurea \\
\hline Phyllostachys heterocycla var. Pubescens & Phyllostachys vivax \\
\hline Phyllostachys iridescens & Phyllostachys vivax f. Aureocaulis \\
\hline
\end{tabular}

Autorizados los ingresos y realizadas las inspecciones sanitarias correspondientes, las plantas fueron distribuidas para su cuidado y preparación a los viveros de INFOR en Concepción, del Jardín Botánico Nacional en Viña del Mar, y de un particular en la zona de Talagante, cercana a Santiago (Figura $N^{\circ} 6$ ).
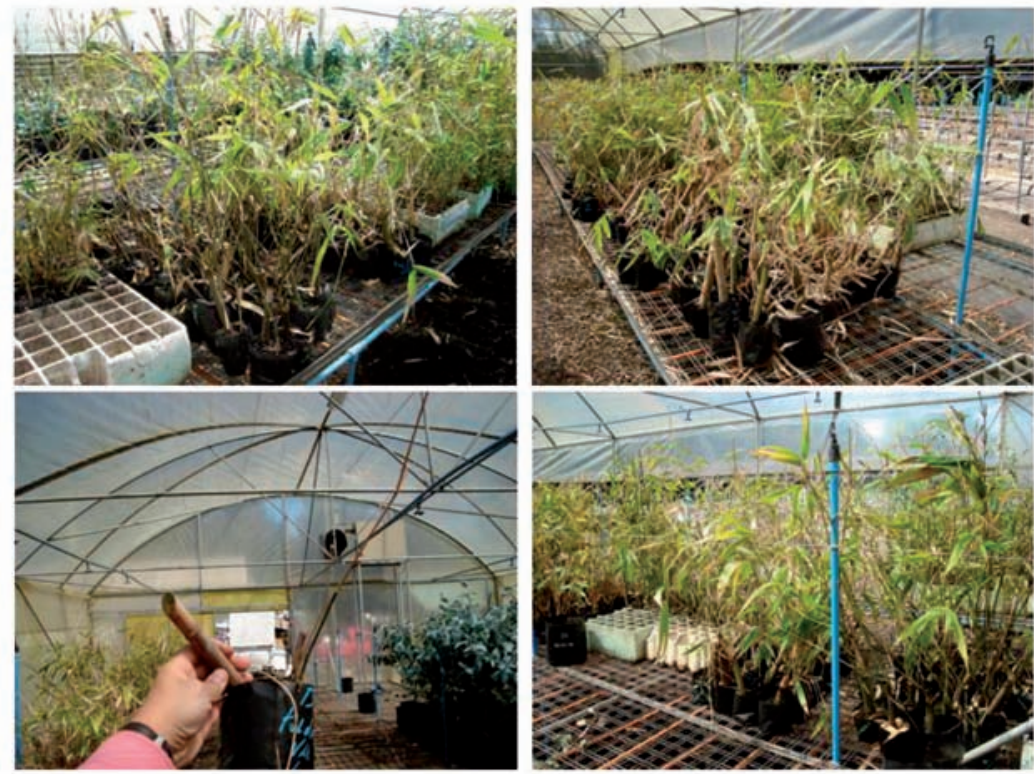

Figura $\mathrm{N}^{\circ} 6$

CUIDADO Y ACONDICIONAMIENTO DE PLANTAS EN VIVERO INFOR EN CONCEPCIÓN 


\section{Instalación de Ensayos}

La limitada disponibilidad de especies y plantas, respecto de la programación inicial, permitió finalmente el establecimiento de 12 ensayos y el empleo de un total de 8 especies y variedades del género Bambusa más la especie control en ellos. Los ensayos fueron establecidos en la temporada 2008.

Se esperaba contar para la temporada 2009 con las especies del género Phyllostachys, para completar los ensayos, tanto en lo referente a especies en ellos como a total de ensayos, cosa que no fue posible dados los inconvenientes antes explicados. Quedaron así pendientes las especies del género Phyllostachys, dos especies del género Bambusa, y dos ensayos en Isla de Pascua y uno en Aysén.

Los propietarios de los predios en cada caso fueron responsables de la preparación de suelos y los cercos, mediante convenios establecidos con ellos.

Junto con la plantación se aplicó un gel (HIDROSORB) en las casillas de plantación a razón de $500 \mathrm{~cm}^{3}$ por casilla y un repelente contra roedores (Mister Cartel) más un fijador de este (Rain out Mister Cartel), producto este último que actúa generando un mal sabor de las hojas ( $2.5 \mathrm{~L}$ del producto en $12.5 \mathrm{~L}$ de agua, más $1 \mathrm{~kg}$ del fijador) (Figura $\mathrm{N}^{\circ} 7$ ).

Establecida la plantación se aplicó un riego de establecimiento y se midió la altura total de las plantas en las parcelas centrales de control (12 plantas). Todas las parcelas fueron marcadas en forma permanente con estacas identificando las especies y el orden de ejecución de las mediciones de control en ellas.

Cada lugar de ensayo cuenta con un croquis de distribución de parcelas y de ubicación del ensayo, una caracterización edafoclimática y la información general de propietario y otros antecedentes. 

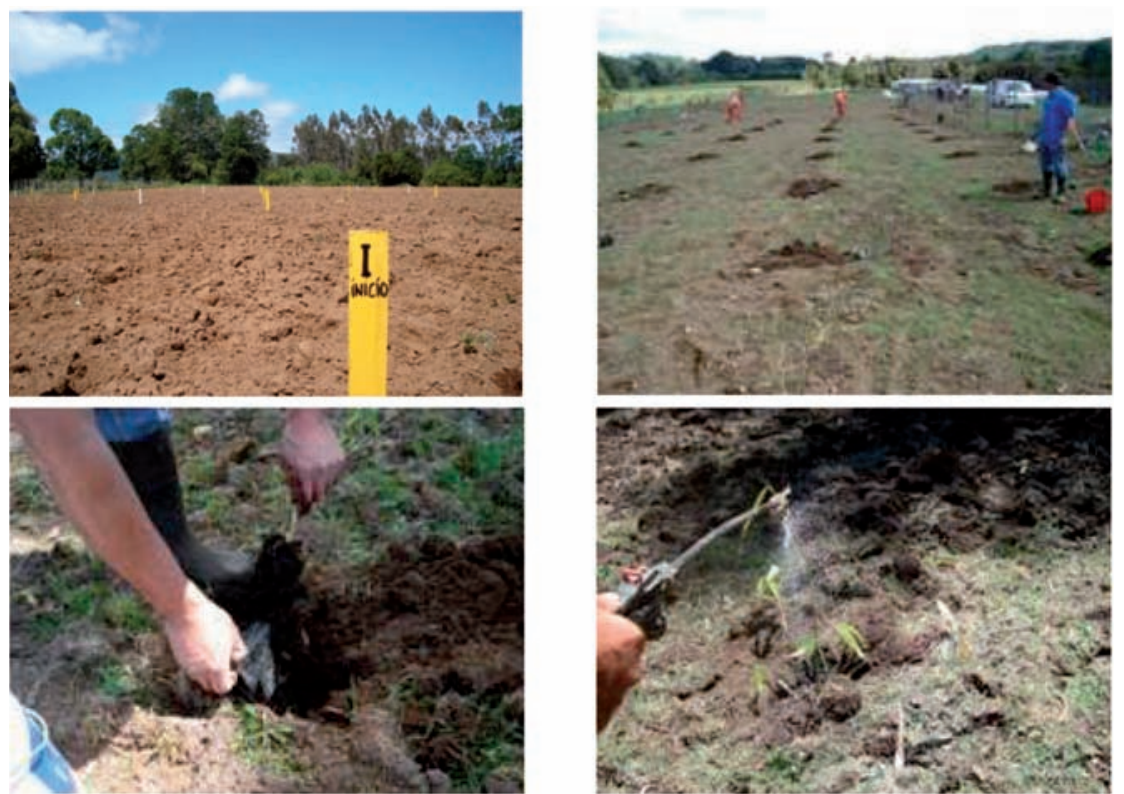

Figura $\mathrm{N}^{\circ} 7$

ASPECTO GENERAL PREPARACIÓN TERRENOS, HOYADURA Y APLICACIÓN DE GEL Y REPELENTE

En el Cuadro $N^{\circ} 6$ se muestra el detalle de ensayos establecidos y las especies y variedades en cada uno de ellos. 
Cuadro $\mathrm{N}^{\circ} 6$

ENSAYOS ESTABLECIDOS TEMPORADA 2008 Y ESPECIES SEGÚN ENSAYO

\begin{tabular}{|c|c|c|c|c|c|c|c|c|c|}
\hline \multirow[b]{2}{*}{ ENSAYO } & \multicolumn{9}{|c|}{ ESPECIES Y VARIEDADES } \\
\hline & $\begin{array}{c}\text { Bambusa } \\
\text { tulda }\end{array}$ & $\begin{array}{l}\text { Bambusa } \\
\text { perviabilis }\end{array}$ & $\begin{array}{c}\text { Bambusa } \\
\text { tulda } \\
\text { var Vittata }\end{array}$ & $\begin{array}{l}\text { Bambusa } \\
\text { tuldoides }\end{array}$ & $\begin{array}{c}\text { Bambusa } \\
\text { ventricosa }\end{array}$ & $\begin{array}{c}\text { Bambusa } \\
\text { vulgaris }\end{array}$ & $\begin{array}{c}\text { Bambusa } \\
\text { vulgaris } \\
\text { var Vittata }\end{array}$ & $\begin{array}{l}\text { Bambusa } \\
\text { multiplex }\end{array}$ & $\begin{array}{c}\text { Chusquea } \\
\text { culeou }\end{array}$ \\
\hline Talagante & $\sqrt{ }$ & $\sqrt{ }$ & $\sqrt{ }$ & $\sqrt{ }$ & $\sqrt{ }$ & $\sqrt{ }$ & $\sqrt{ }$ & $\sqrt{ }$ & $\sqrt{ }$ \\
\hline Curicó & $\sqrt{ }$ & $\sqrt{ }$ & $\sqrt{ }$ & $\sqrt{ }$ & $\sqrt{ }$ & $\sqrt{ }$ & $\sqrt{ }$ & $\sqrt{ }$ & $\sqrt{ }$ \\
\hline Cañete & $\sqrt{ }$ & & & $\sqrt{ }$ & $\sqrt{ }$ & $\sqrt{ }$ & $\sqrt{ }$ & & $\sqrt{ }$ \\
\hline Villarrica & $\sqrt{ }$ & $\sqrt{ }$ & $\sqrt{ }$ & $\sqrt{ }$ & $\sqrt{ }$ & $\sqrt{ }$ & $\sqrt{ }$ & $\sqrt{ }$ & $\sqrt{ }$ \\
\hline Toltén & $\sqrt{ }$ & & & $\sqrt{ }$ & & $\sqrt{ }$ & $\sqrt{ }$ & $\sqrt{ }$ & $\sqrt{ }$ \\
\hline Panguipulli & $\sqrt{ }$ & & $\sqrt{ }$ & $\sqrt{ }$ & $\sqrt{ }$ & $\sqrt{ }$ & $\sqrt{ }$ & & \\
\hline Valdivia & $\sqrt{ }$ & $\sqrt{ }$ & & $\sqrt{ }$ & $\sqrt{ }$ & $\sqrt{ }$ & $\sqrt{ }$ & & \\
\hline Neltume & $\sqrt{ }$ & & $\sqrt{ }$ & $\sqrt{ }$ & & $\sqrt{ }$ & $\sqrt{ }$ & & $\sqrt{ }$ \\
\hline $\begin{array}{l}\text { Puerto } \\
\text { Varas }\end{array}$ & $\sqrt{ }$ & $\sqrt{ }$ & $\sqrt{ }$ & $\sqrt{ }$ & $\sqrt{ }$ & $\sqrt{ }$ & $\sqrt{ }$ & $\sqrt{ }$ & $\sqrt{ }$ \\
\hline Calbuco & $\sqrt{ }$ & & & $\sqrt{ }$ & & $\sqrt{ }$ & $\sqrt{ }$ & $\sqrt{ }$ & $\sqrt{ }$ \\
\hline Castro & $\sqrt{ }$ & & & $\sqrt{ }$ & $\sqrt{ }$ & $\sqrt{ }$ & $\sqrt{ }$ & & $\sqrt{ }$ \\
\hline Chonchi & $\sqrt{ }$ & & $\sqrt{ }$ & $\sqrt{ }$ & & $\sqrt{ }$ & $\sqrt{ }$ & & $\sqrt{ }$ \\
\hline
\end{tabular}

La distribución de especies en los diferentes ensayos se efectuó según la disponibilidad de plantas y en forma acorde con la información reunida sobre las especies y las características edafoclimáticas de cada uno.

En la temporada 2009 se efectuó un replante en los ensayos de Panguipulli y Neltume, donde se habían producido fuertes pérdidas de plantas debido a falta de cuidados por parte de los propietarios de los predios, situación que estos se comprometieron a resolver.

También en la temporada 2009 se envió a Isla de Pascua una partida de plantas para el establecimiento de un ensayo con 7 especies del género Bambusa, las cuales fueron sometidas a cuidado y acondicionamiento en el vivero de la Corporación Nacional Forestal en la isla, el ensayo fue instalado en la temporada 2010 (Cuadro № 7) y el seguimiento está a cargo de esa Corporación. 


\section{Cuadro $\mathrm{N}^{\circ} 7$}

\section{ESPECIES ESTABLECIDAS EN ENSAYO EN ISLA DE PASCUA TEMPORADA 2010}

\begin{tabular}{|l|l|}
\hline Bambusa multiplex & Bambusa ventricosa \\
\hline Bambusa tulda & Bambusa vulgaris \\
\hline Bambusa tulda var. Vittata & Bambusa vulgaris var. Vittata \\
\hline Bambusa tuldoides & \\
\hline
\end{tabular}

\section{Evaluaciones}

Se efectuaron mediciones de control, tomando supervivencia, diámetro y altura de las plantas desde la situación inicial en la temporada 2008 hasta el año 2010 (Cuadro N 8). En cada medición se evaluó también el estado sanitario.

\section{Cuadro $\mathrm{N}^{\circ} 8$ \\ MEDICIONES DE EVALUACIÓN DE LOS ENSAYOS POR AÑO}

\begin{tabular}{|c|c|c|c|c|c|c|c|c|c|}
\hline \multirow{3}{*}{ ENSAYO } & \multicolumn{9}{|c|}{ EVALUACIONES SEGÚN AÑO } \\
\hline & \multicolumn{3}{|c|}{2008} & \multicolumn{3}{|c|}{2009} & \multicolumn{3}{|c|}{2010} \\
\hline & $\begin{array}{c}\text { Supervivencia } \\
(\%)\end{array}$ & $\begin{array}{l}\text { DAC } \\
\text { (cm) }\end{array}$ & $\begin{array}{c}\text { Altura } \\
(\mathrm{m})\end{array}$ & $\begin{array}{c}\text { Supervivencia } \\
(\%)\end{array}$ & $\begin{array}{l}\text { DAC } \\
\text { (cm) }\end{array}$ & $\begin{array}{c}\text { Altura } \\
(\mathrm{m}\end{array}$ & $\begin{array}{c}\text { Supervivencia } \\
(\%)\end{array}$ & $\begin{array}{l}\text { DAC } \\
(\mathrm{cm})\end{array}$ & $\begin{array}{l}\text { Altura } \\
(\mathrm{m}\end{array}$ \\
\hline Talagante & & & & $\sqrt{ }$ & & $\sqrt{ }$ & $\sqrt{ }$ & $\sqrt{ }$ & $\sqrt{ }$ \\
\hline Curicó & $\sqrt{ }$ & & $\sqrt{ }$ & $\sqrt{ }$ & & & & & \\
\hline Cañete & $\sqrt{ }$ & & $\sqrt{ }$ & $\sqrt{ }$ & & & $\sqrt{ }$ & & $\sqrt{ }$ \\
\hline Villarrica & $\overline{\sqrt{ }}$ & & $\sqrt{ }$ & & & & $\sqrt{ }$ & & $\sqrt{ }$ \\
\hline Toltén & $\sqrt{ }$ & & $\sqrt{ }$ & & & & $\sqrt{ }$ & & $\sqrt{ }$ \\
\hline Panguipulli & $\sqrt{ }$ & & $\sqrt{ }$ & & & & $\sqrt{ }$ & & $\sqrt{ }$ \\
\hline Valdivia & $\sqrt{ }$ & & $\sqrt{ }$ & & & & $\sqrt{ }$ & & $\sqrt{ }$ \\
\hline Neltume & $\sqrt{ }$ & & $\sqrt{ }$ & & & & $\sqrt{ }$ & & $\sqrt{ }$ \\
\hline Puerto Varas & $\sqrt{ }$ & & $\sqrt{ }$ & & & & $\sqrt{ }$ & & $\sqrt{ }$ \\
\hline Calbuco & $\sqrt{ }$ & & $\sqrt{ }$ & & & & $\sqrt{ }$ & & $\sqrt{ }$ \\
\hline Castro & $\sqrt{ }$ & & $\sqrt{ }$ & & & & $\sqrt{ }$ & & $\sqrt{ }$ \\
\hline Chonchi & $\sqrt{ }$ & & $\sqrt{ }$ & & & & $\sqrt{ }$ & & $\sqrt{ }$ \\
\hline
\end{tabular}

\section{RESULTADOS}

Las evaluaciones realizadas son las indicadas en el Cuadro $\mathrm{N}^{\circ} 8$. Las mediciones de altura y diámetro no han sido posibles debido a sucesivos daños por heladas, principalmente en el año 2009, a los que han sobrevivido solo los rizomas, que posteriormente han rebrotado. Esto en general impide comparaciones respecto a la situación inicial para evaluar crecimiento, en consecuencia los resultados que se entregan corresponde solo a supervivencia por especie y ensayo, transcurridos dos años de la plantación (Cuadro N 9). Además, en el caso particular de los ensayos de Panguipulli y Neltume, buena parte de la 
plantación fue repuesta en el año 2009.

Indudablemente son necesarias mediciones posteriores que permitan apreciar crecimiento, cosa que no fue posible debido a los fuertes daños por heladas. Respecto de la supervivencia de las especies en cada ensayo y a través de ellos desde Santiago a Chiloé, no se aprecian tendencias claras que serían previsibles por el aumento de las precipitaciones y reducción de las temperaturas de norte a sur.

Destacan las especies Bambusa ventricosa y Bambusa tuldoides, que alcanzan valores interesantes respecto a la sobrevivencia media de todos los ensayos en que fueron incluidas (52,1 y $51,4 \%$, respectivamente), muy similares al $50 \%$ alcanzado por la especie testigo, coligüe, y con valores bastante altos en algunos de ellos (Figura $\mathrm{N}^{\circ} 8$ ).

Negativamente destaca Bambusa perviabilis con mortalidad completa en todos los ensayos en que se la incluyó. Bambusa vulgaris, Bambusa vulgaris var. Vittata y Bambusa multiplex, muestran supervivencias por bajo el $15 \%$ en promedio, la primera en todos los ensayos en que está presente, la segunda registra un buen resultado en algunos ensayos, principalmente en la zona de Valdivia, y la tercera sólo en uno, Talagante.

Bambusa tulda, en tanto, muestra buenos resultados en la mayoría de los ensayos, estando presente en todos ellos, pero su supervivencia media cae debido al nulo resultado en tres de ellos. Algo semejante ocurre con Bambusa tuldoides. Ambas especies muestran una buena tendencia, pese a los daños por heladas del año 2009. 


\section{Cuadro $\mathrm{N}^{\circ} 9$ \\ SUPERVIVENCIA POR ESPECIE Y ENSAYO}

\begin{tabular}{|c|c|c|c|c|c|c|c|c|c|}
\hline \multirow{2}{*}{ ENSAYo } & \multicolumn{7}{|c|}{ SUPERVIVENCIA } \\
\cline { 2 - 11 } & $\begin{array}{c}\text { Bambusa } \\
\text { tulda }\end{array}$ & $\begin{array}{c}\text { Bambusa) } \\
\text { perviabilis }\end{array}$ & $\begin{array}{c}\text { Bambusa } \\
\text { tulda } \\
\text { var. Vittata }\end{array}$ & $\begin{array}{c}\text { Bambusa } \\
\text { tuldoides }\end{array}$ & $\begin{array}{c}\text { Bambusa } \\
\text { ventricosa }\end{array}$ & $\begin{array}{c}\text { Bambusa } \\
\text { vulgaris }\end{array}$ & $\begin{array}{c}\text { Bambusa } \\
\text { vulgaris var. } \\
\text { Vittata }\end{array}$ & $\begin{array}{c}\text { Bambusa } \\
\text { multiplex }\end{array}$ & $\begin{array}{c}\text { Chusquea } \\
\text { culeou }\end{array}$ \\
\hline Talagante & 41,7 & 0,0 & 33,3 & 75,0 & 75,0 & 0,0 & 0,0 & 58,3 & 58,3 \\
\hline Curicó & 0,0 & 0,0 & 0,0 & 0,0 & 33,3 & 8,3 & 0,0 & 0,0 & 0,0 \\
\hline Cañete & 41,7 & & & 83,3 & 41,7 & 25,0 & 41,7 & & 25,0 \\
\hline Villarrica & 0,0 & 0,0 & 0,0 & 0,0 & 0,0 & 0,0 & 0,0 & 0,0 & 0,0 \\
\hline Toltén & 16,7 & & & 0,0 & & 8,3 & 0,0 & 0,0 & 0,0 \\
\hline Panguipulli & 41,7 & & 8,3 & 41,7 & 0,0 & 0,0 & 0,0 & & \\
\hline Valdivia & 41,7 & 0,0 & & 75,0 & 91,7 & 16,7 & 41,7 & & \\
\hline Neltume & 66,7 & & 91,7 & 100,0 & & 0,0 & 66,7 & & 75,0 \\
\hline Puerto Varas & 41,7 & 0,0 & 8,3 & 91,7 & 91,7 & 8,3 & 8,3 & 8,3 & 83,3 \\
\hline Calbuco & 41,7 & & & 83,3 & & 8,3 & 0,0 & 8,3 & 75,0 \\
\hline Castro & 91,7 & & & 66,7 & 83,3 & 0,0 & 0,0 & & 83,3 \\
\hline Chonchi & 0,0 & & 16,7 & 0,0 & & 0,0 & 0,0 & & 100,0 \\
\hline Promedio & $\mathbf{3 5 , 4}$ & $\mathbf{0 , 0}$ & $\mathbf{2 2 , 6}$ & $\mathbf{5 1 , 4}$ & $\mathbf{5 2 , 1}$ & $\mathbf{6 , 3}$ & $\mathbf{1 3 , 2}$ & $\mathbf{1 2 , 5}$ & $\mathbf{5 0 , 0}$ \\
\hline
\end{tabular}

Nota: Celda sin información indica especie no incluida en el ensayo.

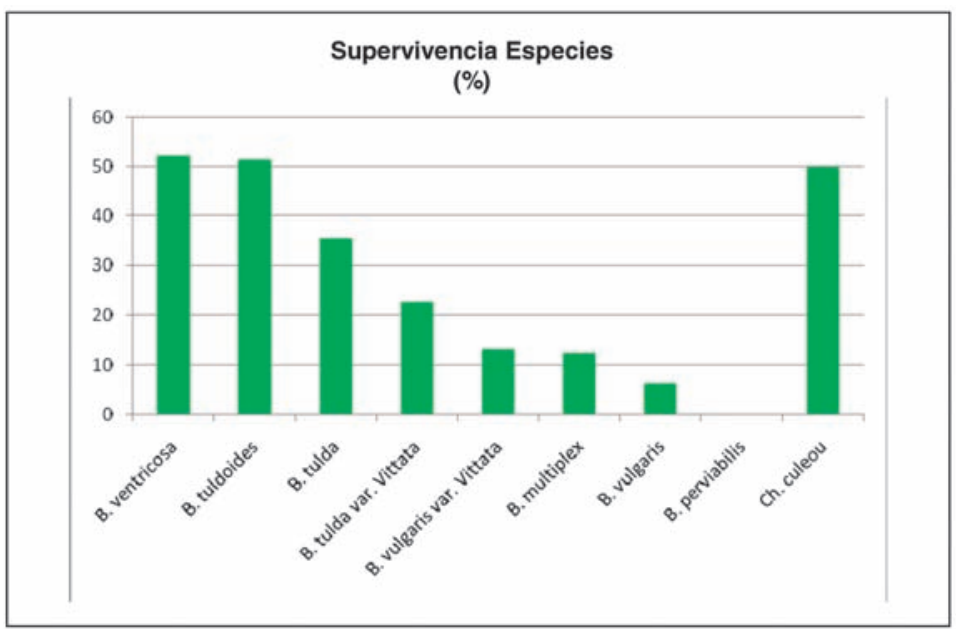

Figura $\mathrm{N}^{\circ} 8$

SUPERVIVENCIA MEDIA DE LAS ESPECIES 2010 
Se efectuó además una evaluación por macro zonas, agrupando los ensayos según Zona Centro-Sur, Zona Sur y Zona Insular-Sur, obteniéndose los resultados indicados en el Cuadro $N^{\circ} 10$ y la Figura $N^{\circ} 9$.

\section{Cuadro $\mathrm{N}^{\circ} 10$ \\ SUPERVIVENCIA MEDIA DE LAS ESPECIES SEGÚN MACRO ZONA 2010}

\begin{tabular}{|c|c|c|c|c|c|c|c|c|c|}
\hline & \multicolumn{7}{|c|}{ SUPERVIVENCIA (2010) } \\
\cline { 2 - 10 } Zona & $\begin{array}{c}\text { Bambusa } \\
\text { tulda }\end{array}$ & $\begin{array}{c}\text { Bambusa } \\
\text { perviabilis }\end{array}$ & $\begin{array}{c}\text { Bambusa } \\
\text { tulda var. } \\
\text { Vittata }\end{array}$ & $\begin{array}{c}\text { Bambusa } \\
\text { tuldoides }\end{array}$ & $\begin{array}{c}\text { Bambusa } \\
\text { ventricosa }\end{array}$ & $\begin{array}{c}\text { Bambusa } \\
\text { vulgaris }\end{array}$ & $\begin{array}{c}\text { Bambusa } \\
\text { vulgaris } \\
\text { var. Vittata }\end{array}$ & $\begin{array}{c}\text { Bambusa } \\
\text { multiplex }\end{array}$ & $\begin{array}{c}\text { Chusquea } \\
\text { culeou }\end{array}$ \\
\hline Centro-Sur & 27,8 & 0,0 & 16,7 & 52,8 & 50,0 & 11,1 & 13,9 & 29,2 & 27,8 \\
\hline Sur & 35,7 & 0,0 & 27,1 & 56,0 & 45,8 & 6,0 & 16,7 & 4,2 & 46,7 \\
\hline Insular-Sur & 45,8 & 0,0 & 16,7 & 33,3 & 83,3 & 0,0 & 0,0 & 0,0 & 91,7 \\
\hline
\end{tabular}

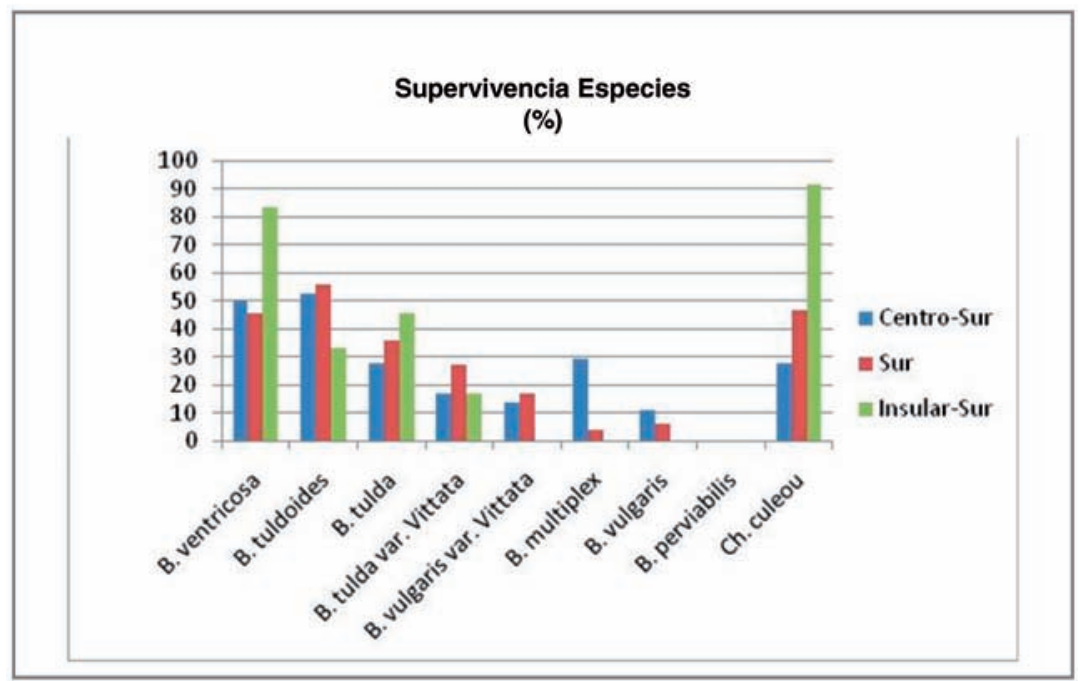

Figura $\mathrm{N}^{\circ} 9$

SUPERVIVENCIA MEDIA DE LAS ESPECIES SEGÚN MACROZONA 2010 


\section{DISCUSIÓN Y CONCLUSIONES}

De las especies probadas destacan claramente tres que han mostrado una buena respuesta en prácticamente todos los ensayos en que se las incluyó, estas son Bambusa tulda, Bambusa tuldoides y Bambusa ventricosa.

Por el contrario, Bambusa perviabilis muestra mortalidad completa en todos los ensayos en que se la incluyó y Bambusa vulgaris, Bambusa vulgaris var. Vittata y Bambusa multiplex, muestran supervivencias por bajo el $15 \%$ en promedio, la primera en todos los ensayos en que está presente, la segunda registra un buen resultado en algunos ensayos, principalmente en la zona de Valdivia, y la tercera sólo en uno, Talagante.

Las pérdidas sufridas en los ensayos, muy importantes en algunos de ellos, se deben principalmente a daños por heladas, particularmente severas en el año 2009.

Lamentablemente no se alcanzó a incorporar a los ensayos las especies del género Phyllostachys, de mayor resistencia a frío que las probadas del género Bambusa.

Los resultados por macro zona geográfica permiten una primera aproximación a las posibilidades de uso de estas especies en plantaciones comerciales para diferentes fines (Cuadro No 11).

No obstante, estos ensayos indudablemente deben ser evaluados durante un período de tiempo más prolongado, aunque descartando los ensayos de Villarrica, en el que al año 2010 no había supervivencia de especies, y los de Curicó, Toltén y Chonchi, perdidos en su casi totalidad también.

\section{Cuadro $N^{\circ} 11$ \\ POSIBILIDADES DE USO DE LAS ESPECIES SEGÚN MACROZONA GEOGRÁFICA}

\begin{tabular}{|l|c|c|c|l|}
\hline \multirow{2}{*}{ ESPECIE } & \multicolumn{3}{|c|}{ MACRO ZONA } & \multirow{2}{*}{ USOS PRINCIPALES } \\
\cline { 2 - 4 } & Centro Sur & Sur & Insular Sur & \\
\hline Bambusa ventricosa & $\sqrt{ }$ & $\sqrt{ }$ & $\sqrt{ }$ & Uso múltiple \\
\hline Bambusa tuldoides & $\sqrt{ }$ & $\sqrt{ }$ & $\sqrt{ }$ & Fibras, brotes comestibles \\
\hline Bambusa tulda & $\sqrt{ }$ & $\sqrt{ }$ & $\sqrt{ }$ & Construcción \\
\hline Bambusa tulda var. Vittata & $\sqrt{ }$ & $\sqrt{ }$ & $X$ & Uso múltiple \\
\hline Bambusa vulgaris var. Vittata & $X$ & $X$ & $X$ & \\
\hline Bambusa multiplex & $\sqrt{ }$ & $X$ & $X$ & Ornamental \\
\hline Bambusa vulgaris & $X$ & $X$ & $X$ & \\
\hline Bambusa perviabilis & $X$ & $X$ & $X$ & \\
\hline
\end{tabular}

$\sqrt{ } \sqrt{ }$ : Mejor resultado de supervivencia $\quad X \quad$ : No recomendable

Sólo en cuatro de los doce ensayos se incluyeron todas las especies disponibles; Talagante, Curicó, Villarrica y Puerto Varas. 
En Curicó y Villarrica la pérdida de supervivencia de plantas fue total o casi total, en Puerto Varas cuatro especies muestran una supervivencia buena o aceptable y en Talagante, seis de las nueve especies muestran resultados que ameritan mayor seguimiento, pese a la fuerte reducción de la supervivencia e incluso de la altura en algunas de ellas, al segundo año, debido a las heladas del primero (Cuadro $\mathrm{N}^{\circ} 12$ ).

Bambusa vulgaris var. Vittata, Bambusa vulgaris y Bambusa perviabilis son las tres especies sin supervivencia al segundo año en el ensayo de Talagante y su respuesta es similar en todos los lugares de ensayo.

Para la continuación de trabajos de investigación sobre la introducción y adaptación de Bambusaceas, el seguimiento de al menos los ensayos de Talagante y Puerto Varas, en especial del primero dado el interés y compromiso del propietario del predio en que se ubica, y su complementación, incorporando aquellas especies en reserva, en cuarentena en el Jardín Botánico Nacional, sería muy interesante.

\section{Cuadro $\mathrm{N}^{\circ} 12$ \\ VALOR PROMEDIO DE VARIABLES EVALUADAS EN ENSAYO TALAGANTE SEGÚN ESPECIE}

\begin{tabular}{|c|c|c|c|c|}
\hline \multirow{3}{*}{ ESPECIE } & \multicolumn{4}{|c|}{ PARAMETROS MEDIOS } \\
\hline & \multicolumn{2}{|c|}{$\begin{array}{c}\text { SUPERVIVENCIA } \\
(\%)\end{array}$} & \multicolumn{2}{|c|}{$\begin{array}{l}\text { ALTURA } \\
(\mathrm{cm})\end{array}$} \\
\hline & 2009 & 2010 & 2009 & 2010 \\
\hline Bambusa tulda & 75,0 & 41,7 & 40,7 & 19,0 \\
\hline Bambusa tuldoides & 100,0 & 75,0 & 76,9 & 75,0 \\
\hline Bambusa tulda var. Vittata & 100,0 & 33,3 & 44,1 & 26,5 \\
\hline Bambusa ventricosa & 91,7 & 75,0 & 47,9 & 98,2 \\
\hline Bambusa multiplex & 66,7 & 58,3 & 39,0 & 28,0 \\
\hline Bambusa vulgaris & 83,3 & 0,0 & 62,1 & \\
\hline Bambusa vulgaris var. Vittata & 100,0 & 0,0 & 64,5 & \\
\hline Bambusa perviabilis & 100,0 & 0,0 & 48,3 & \\
\hline Chusquea culeou & 91,7 & 58,3 & 31,4 & 40,3 \\
\hline
\end{tabular}

El material en reserva y las especies existentes en los ensayos de Talagante y Puerto Varas, vistas las grandes dificultades encontradas para la importación e internación de Bambusaceas al país, es de gran valor, tanto en términos de su evaluación a futuro como de fuente de propágulos para ensayos complementarios.

Experiencias anteriores en el país, como las del Bambucetum de la Universidad Austral de Chile en Valdivia y las plantaciones que mantiene el propietario del predio donde se ubicó el ensayo de Talagante, permiten observar que son las especies del género 
Phyllostachys las que logran los mejores desarrollos, siendo muy similares a los que registran en sus áreas de origen (China). Esto pone en relieve el valor del material en reserva que se encuentra concluyendo el período de cuarentena en el Jardín Botánico Nacional en Viña del Mar.

\section{REFERENCIAS}

Botero, L., 2006. Manual Curso sobre Industrialización del bambú. COMPYMEFOR, Argentina. 117p.

Campos, J.; Peñaloza, R.; Kahler, C.; Poblete, H.; Cabrera, J. (eds.), 2003. Bambú en Chile. Corporación de Investigación Tecnológica de Chile, Universidad Austral de Chile. $144 p$.

Dransfield, S.; Widjaja, E. (eds.)., 1995. Plant Resources of South-East Asia № 7. Bamboos. Backhuys Publishers, leiden. 189p.

Farrelly, David, 1984. The Book of Bamboo. Sierra Club Books.

Gratani, Loretta; Crescente, Maria Fiore; Varone, Laura; Fabrini, Giuseppe and Digiulio, Eleonora, 2008. "Growth pattern and photosynthetic activity of different bamboo species growing in the Botanical Garden of Rome". Flora 203: 77-84.

Hidalgo, L. O., 2003. Bamboo: the gift of the gods. Ed. D’VINNI. Colombia. 555p.

INBAR, 2007. International Network for Bamboo and Ratan [Fecha de consulta: 15 Junio 2007]. Disponible en: http://www.inbar.int

INBAR, 2010. International Network for Bamboo and Ratan [Fecha de consulta: 01 Abril 2010]. Disponible en: http://www.inbar.int

INFOR, 2010. Anuario Forestal 2010. Boletín Estadístico 128. Instituto Forestal, Santiago, Chile. 134p.

Oprins, J.; van Trier, H., 2002. Bamboo. A Material for Landscape and Garden Design. Birkhäuser Architecture Ed. 143p.

Rao, R.; Sastry, C. (eds.)., 1995. Proceedings of the Vth International Bamboo Workshop and the IV International Bamboo Congress: Bamboo, People and the Environment. Ubud, Bali, Indonesia., 19-22 June.

Singh, H.; Dadlani, N. (eds.)., 2004. Abstracts VII World Bamboo Congress. World Bamboo Organization and Government of India. New Delhi, India. February 28 - March 4. $64 p$.

Villegas, M. (ed.)., 1996. Bambusa guadua. Villegas Editores. Bogotá, Colombia. Segunda edición. 175p. 
